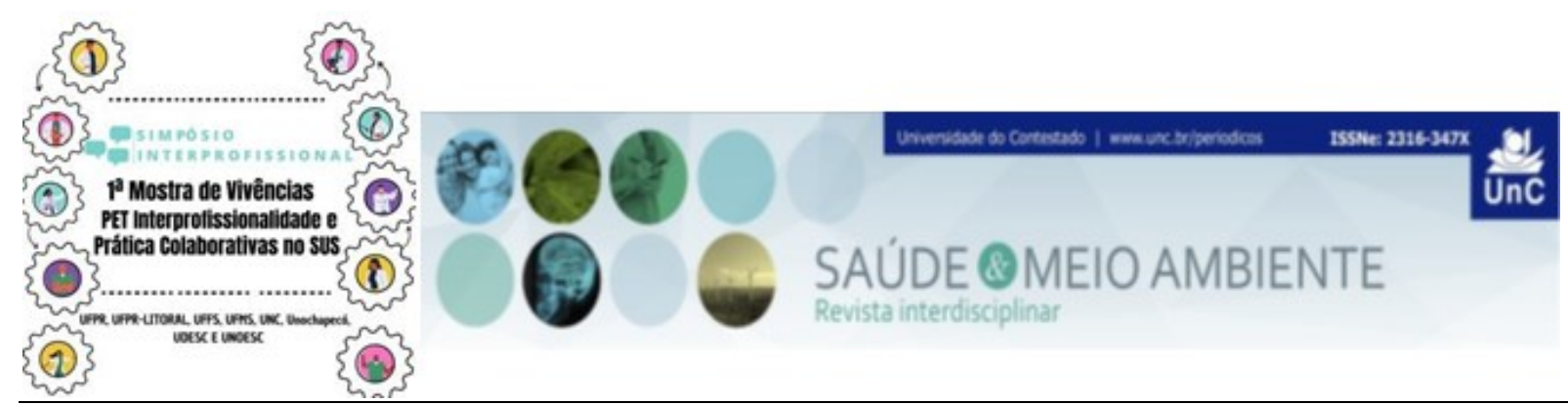

\title{
DESAFIOS E POSSIBILIDADES PARA A MANUTENÇÃO DO PROGRAMA DE EDUCAÇÃO PELO TRABALHO PARA A SAÚDE (PET-Saúde Interprofissionalidade) DURANTE A PANDEMIA
}

Projeto 139

Andressa Karkow Crivellaro ${ }^{1}$ Elias Matheus Baggio Valgoi ${ }^{2}$

Èliton Vitor Miranda ${ }^{3}$

Nádia Kunkel Szinwelski ${ }^{4}$

Cristiano Padilha ${ }^{5}$

Leonardo Cé 6

Tania Inez Mariga Schaefer ${ }^{7}$

\section{RESUMO}

Introdução: A pandemia causada pelo SARS-CoV-2 colocou o mundo em isolamento social e instiga incertezas, tanto em relação às consequências da disseminação do vírus como a forma como nos relacionamos. O Programa de Educação pelo Trabalho para a Saúde (PET-Saúde Interprofissionalidade - 2019/2021) tem, dentre suas finalidades, formar profissionais mais aptos para o trabalho colaborativo em saúde ${ }^{1}$. Objetivos: Relatar a experiência vivenciada e refletir sobre os desafios e as possibilidades para a manutenção do Programa durante a pandemia do novo Coronavírus Metodologia: Estudo do tipo relato de experiência, de abordagem qualitativa descritiva, baseado nas percepções dos integrantes do Programa sobre o impacto da pandemia e como isso se reflete do contexto do programa. Resultados: Com a adoção das medidas de isolamento social impostas em função da pandemia, as atividades do Programa que eram presenciais e em equipe, como a participação nos grupos terapêuticos e o projeto de pesquisa com os profissionais em forma de grupo focal, foram suspensos, obrigando à readequação da forma de atuação para a esfera virtual, passando a ser conduzida através de plataformas e ferramentas digitais, como Google Meet, WhatsApp, Jamboard e Canva. Essas novas formas de abordagens no ensino-aprendizagem apresentaram algumas questões desafiadoras,

\footnotetext{
${ }^{1}$ Acadêmica de Medicina. Unochapecó. Santa Catarina. Brasil. E-mail: akcrivellaro@gmail.com

2 Acadêmico de Medicina. Unochapecó. Santa Catarina. Brasil. E-mail: elias valgoi@unochapeco.edu.br

${ }^{3}$ Acadêmico de Enfermagem. Unochapecó. Santa Catarina. Brasil. E-mail: eliton.m@unochapeco.edu.br

4 Tutora coordenadora. Unochapecó. Santa Catarina. Brasil. E-mail: nadiaks@unochapeco.edu.br

5 Tutor. Unochapecó. Santa Catarina. Brasil. E-mail: padilhacristiano@unochapeco.edu.br

${ }^{6}$ Preceptor. Prefeitura Municipal de Chapecó. Santa Catarina. Brasil. E-mail: chapeco.sc.leonardo.ce@gmail.com

7 Preceptora. Prefeitura Municipal de Chapecó. Santa Catarina. Brasil. E-mail: taniamariga@gmail.com
} 
entre elas: a dependência da estabilidade da rede de internet; a não visualização da linguagem corporal; e exigência de maior comprometimento e autonomia dos atores. Além disso, os recém ingressos no grupo PET, só conhecem os colegas virtualmente e não puderam vivenciar a rotina na Unidade de Saúde e as reuniões e atividades presenciais com o grupo. Também devemos considerar os impactos emocionais mediante o isolamento social. Quanto aos aspectos benéficos no ensino-aprendizado à distância, percebemos os seguintes: o desenvolvimento de novas habilidades com meios tecnológicos; maior flexibilização de horário; e o não deslocamento para as reuniões, com menor risco de exposição à violência urbana e ao trânsito. Destacamos como principais produções nesse período, a participação ativa do grupo no curso de atualização em desenvolvimento docente para a Educação Interprofissional em Saúde e a criação de materiais informativos para serem disponibilizados para os usuários via Whatsapp. Considerações finais: Frente ao atual panorama mundial, entendemos que a adaptação e flexibilização do processo de ensino-aprendizagem é necessária. Contudo, é senso comum entre o grupo, que mesmo a melhor e mais completa ferramenta digital não substitui o contato pessoal, as relações mais próximas e humanizadas, possuindo essas, maior potencial para tornar a comunicação entre os participantes do Programa PET-Saúde interprofissionalidade mais assertiva e efetiva.

Palavras-chave: Educação interprofissional. Pandemia. Saúde.

\section{REFERÊNCIAS}

1. Costa MV, Peduzzi M, Freire Filho JR, Silva CBG. Educação interprofissional em saúde. Natal: SEDIS-UFRN; 2018. 